\title{
७MONÇÕES

\section{Cooperação Internacional para o Desenvolvimento e Políticas Públicas: um campo de batalha pela autoridade do conceito de desenvolvimento internacional}

International Cooperation for Development and Public Policies: A battlefield for the authority of the international development concept

Cooperación Internacional para el Desarrollo y Políticas Públicas: un campo de batalla por la autoridad del concepto de desarrollo internacional

\author{
Chyara Sales Pereira \\ Professora do Departamento de Relações \\ Internacionais da Pontifícia Universidade \\ Católica de Minas Gerais - PUC MINAS \\ Belo Horizonte- Minas Gerais, Brasil \\ E-mail: chyarasp@gmail.com \\ Orcid: Orcid - 0000-0001-7600-7362
}

\begin{abstract}
Resumo: $O$ argumento central deste texto é ancorado na premissa de que a Cooperação Internacional para o Desenvolvimento (CID) é um campo político fundamental para as relações internacionais. Isto porque ela é o lugar onde as batalhas pela autoridade do conceito de desenvolvimento internacional, bem como a sua operacionalização, podem ser identificadas, refletindo diretamente na agenda das políticas públicas implementadas nos países recebedores dessas ofertas. A CID se consolida na agenda internacional, após a Segunda Grande Guerra, no interior do aparato institucional das Nações Unidas. Expressa na Ajuda Oficial para o Desenvolvimento, é percebida como um instrumento de redução das desigualdades internacionais e de modernização socioeconômica, bem como um incentivo à paz e à estabilidade sistêmica. No quadro de referência da Guerra Fria, a cooperação internacional é entendida como um recurso para a redução de conflitos e anteparo para a expansão do bloco soviético. $O$ fim da Guerra Fria, a derrocada soviética e a diversificação da agenda internacional - proporcionada pela interdependência entre Estados e entre sociedades -, bem como a projeção dos chamados países emergentes, reforçou uma relação de disputa entre as organizações internacionais protagonistas desse campo (ONU e OCDE) desde o final dos anos 1990, redesenhando as fronteiras do desenvolvimento internacional, bem como das políticas públicas que foram, a partir dele, formuladas e implementadas.
\end{abstract}


Palavras-chave: Cooperação para o Desenvolvimento Internacional; Campo político; Políticas Públicas.

\begin{abstract}
The central argument of this text is anchored in the premise that International Cooperation for Development (CID) is a fundamental political field of international relations, where the authority battles the international development concept and its operationalization, we can be identified, directly reflected on the agenda. the public policies implemented in the countries receiving this offer. CID is consolidated on the international agenda, after the Second Great War, not within the institutional apparatus of the United Nations. It expresses an Official Aid for Development, seen as an instrument for the reduction of international inequalities and a means of socioeconomic modernization, as an incentive for peace and systemic stability. There is no reference to the Cold War, to international cooperation and understood, also, as a resource for the reduction of conflicts and before the expansion of the Soviet bloc. On the end of the Cold War, the Soviet overthrow and the diversification of the international agenda, provided by the interdependence between States and between societies, as well as the projections of two so-called emerging countries, reinforcing a dispute relationship between the international organizations protagonists from the field - UN and OECD - Since the end of two years 1990, redesigning the borders of international development, they have been the public policies that have been formulated and implemented from them.
\end{abstract}

Keywords: Cooperation for International Development; Political field; Public Policy.

Resumen: La Cooperación para el Desarrollo (CID) es un campo político fundamental para las relaciones internacionales. Esto se debe a que es el lugar donde se pueden identificar las batallas por la autoridad del concepto de desarrollo internacional, así como su operacionalización, reflejándose directamente en la agenda de políticas públicas implementadas en los países receptores de estas ofertas. La CID se consolida en la agenda internacional, después de la Segunda Guerra Mundial, dentro del aparato institucional de Naciones Unidas. Expresada en la Ayuda Oficial al Desarrollo, se percibe como un instrumento para reducir las desigualdades internacionales y para la modernización socioeconómica, así como un incentivo para la paz y la estabilidad sistémica. En el marco de referencia de la Guerra Fría, la cooperación internacional se entiende como un recurso para la reducción de conflictos y un amortiguador para la expansión del bloque soviético. El fin de la Guerra Fría, la debacle soviética y la diversificación de la agenda internacional - proporcionada por la interdependencia entre Estados y entre sociedades -, así como la proyección de los llamados países emergentes, reforzaron una relación de disputa entre las organizaciones internacionales protagonistas en este campo (ONU y OCDE) desde finales de la década de 1990, redefiniendo las fronteras del desarrollo internacional, así como las políticas públicas que, a partir de él, se formularon e implementaron.

Palabras clave: Cooperación para el Desarrollo Internacional; Campo político; Políticas Públicas. 


\section{INTRODUÇÃO}

Não se pode dizer que a CID tenha sido, em algum momento, agenda prioritária da política internacional, mas se deve reconhecer que ela desempenhou importante papel em pelo menos três momentos da história: (a) após a Segunda-Guerra, quando recebeu forte investimento para o seu processo de institucionalização, principalmente por parte dos Estados Unidos, em sua estratégia de conter avanços do comunismo; (b) ao final da Guerra Fria, quando a onda do otimismo liberal disseminou a crença de que, a partir daquele momento, se deveria priorizar investimentos no desenvolvimento de países africanos, latino-americanos, asiáticos e do Leste Europeu; (c) no início do século XXI, quando se tem um novo alvorecer da cooperação estabelecida pelos países do Sul com reivindicações de mudanças das relações com os países desenvolvidos.

Assim, o argumento central deste texto se desenvolve a partir do entendimento de que a Cooperação Internacional para o Desenvolvimento (CID) é um fundamental campo político das relações internacionais, onde batalhas pela autoridade do conceito de desenvolvimento internacional e sua operacionalização podem ser identificadas, refletindo diretamente na agenda das políticas públicas implementadas nos países recebedores dessas ofertas. Fez-se a opção por entendê-la como um campo político, nos termos de Pierre Bourdieu (2003), onde são identificadas batalhas pela legitimidade, autoridade e recursos materiais. A partir desse entendimento, o presente artigo realiza uma historiografia do processo de constituição da Cooperação Internacional para o Desenvolvimento com o intuito de analisar os principais marcos desse processo e perceber de que maneira se situam os conceitos de desenvolvimento que orientam as políticas públicas implementadas nos países do sul, com a intenção de propiciar o desenvolvimento e a modernização de suas estruturas sociais.

Entendemos que, após o final dos anos 1990, em função de um novo fôlego da Cooperação Sul/Sul, dentre outros elementos, a batalha por poder no campo político entre ONU e OCDE se acirram, alterando as fronteiras do desenvolvimento internacional. Tal 
processo traz implicações diretas para a natureza de políticas públicas formuladas e implementadas e o pressuposto para que isso aconteça é que a OCDE é claramente um ambiente de representatividade dos interesses dos agentes da tradicional Cooperação Norte/Sul; enquanto a ONU representaria os agentes da Cooperação Sul/Sul. Assim, a questão-problema que guia esse raciocínio é: como uma disputa política estabelecida entre ONU e Banco Mundial/OCDE no campo da CID, a partir do final dos anos 1990, acirra-se com a intensificação dos diálogos no âmbito da Cooperação Sul/Sul?

Para tanto, o artigo está estruturado da seguinte maneira: primeiro, faz-se uma historiografia da Cooperação Internacional para o Desenvolvimento desde a sua concepção até o final dos anos 1990, com o objetivo de entender as nuances das relações de interesses e poder nas quais os atores envolvidos competem por autoridade, reconhecimento e recursos materiais. Nesse contexto, o desenvolvimento se torna o elemento que permite a universalização da lógica de modernização social. Em seguida, discute-se a CID como um campo político - na perspectiva de Pierre Bourdieu - e o embate de forças, realçado a partir do final dos anos 1990, entre a ONU e a OCDE. Ao final, passa-se para as considerações finais.

\section{COOPERAÇÃO INTERNACIONAL PARA O DESENVOLVIMENTO: UMA BREVE HISTORIOGRAFIA DE UM CAMPO DE BATALHA PELA AUTORIDADE DO DESENVOLVIMENTO INTERNACIONAL E SUA OPERACIONALIZAÇÃO}

A cooperação internacional para o desenvolvimento se difundiu na sociedade global por meio de organizações internacionais e intergovernamentais, agências estatais e Estados. Primeiramente, institucionalizou-se nas Nações Unidas, momento em que os Estados do Norte se comprometeram a transferir, por meio das agências multilaterais, conhecimentos técnicos e recursos destinados à modernização de países pobres e subdesenvolvidos. Esse comprometimento se justifica por relações de interesses e poder, nas quais os atores envolvidos competem por autoridade, reconhecimento e recursos materiais. Conhecida como 
Cooperação Norte-Sul (CNS), a oferta de cooperação teve, no marco de sua concepção, o desenvolvimento dos Estados capitalistas centrais como modelo, cuja concessão estava condicionada à erradicação da pobreza, ao respeito aos direitos humanos e fundamentais, etc., e, como ideal regulatório, a promoção da paz na sociedade internacional.

No presente artigo, optou-se por entender a CID como um campo político e, portanto, permeado por relações de poder - em que inúmeros atores competem por legitimidade, reconhecimento e recursos materiais. Estruturou-se um grande arranjo institucional em torno dos ideais regulatórios da paz e da igualdade na sociedade internacional, envolvendo organizações internacionais, entidades de mercado, Estados, organizações não governamentais e regras. As regras vigentes são difundidas a partir de instituições capazes de alterar interesses e preferências dos atores, gerando custos de transação numa situação de deserção. Tal constatação é interessante, pois o próprio desenvolvimento internacional assume a qualidade de regra nesse sistema na perspectiva de que lhe é conferida capacidade para alterar uma estrutura social por meio de práticas estipuladas por um conjunto de diretrizes e procedimentos que viabilizam a realização da cooperação. Assim, esse se torna uma das principais alternativas para a modernização de países pobres e subdesenvolvidos, de forma que os atores envolvidos dispendam recursos de mercado e de conhecimento nesse processo.

Nesse primeiro momento de institucionalização da CID - a partir de uma classificação do mundo entre países desenvolvidos e em desenvolvimento -, há a disseminação da ideia de desenvolvimento internacional num caráter universalizante, que se torna, ao mesmo tempo, fonte de entendimento da realidade (conferindo-Ihe sentido e significado) e conteúdo de formulação de políticas públicas, incorporadas nas agendas de modernização social, favorecendo a reprodução dos princípios do livre mercado. Na perspectiva deste estudo, isso só é possível porque o desenvolvimento internacional pode ser entendido nos termos de Giddens (1989), ou seja, como uma regra superficial, já que possui capacidade de oferecer, simultaneamente, uma orientação para as relações entre os agentes, isto é, um modelo de cognição por meio do qual estes mesmos agentes conferem sentido a eles mesmos, às suas 
relações, à relação com o mundo e um princípio moral para o seu comportamento (GIDDENS, 1989).

Assim, o ideário do desenvolvimento internacional ligado à percepção de modernização social por meio dos princípios do livre mercado cria espaços de "entendimentos normativos intersubjetivos" entre as organizações como OCDE, ONU e outras, resultando na disseminação de padrões de comportamento "apropriado" para se promover a Cooperação Internacional para o Desenvolvimento. Assim, pode-se dizer que as organizações, no campo político da Cooperação Internacional para o Desenvolvimento, atuam como "professores" de normas, contribuindo para a socialização dos Estados na aceitação de valores e preferências (BARNETT e FINNEMORE, 1996).

Isso porque, recorrendo ao raciocínio de Bourdieu (1983), um sistema simbólico, estruturante de um padrão cognitivo, só consegue exercer seu poder de conhecimento e comunicação porque é estruturado em uma linguagem que expressa uma visão de mundo. Esta, ao ser difundida, possibilita a produção de um consenso em torno de seu discurso e a legitimação de sua operacionalização, garantindo sua inserção nas sociedades sobre as quais atua e conformando padrões de comportamento e decisão necessários para a sua reprodução.

É por isso que julgamos pertinente discutir a cooperação internacional para o desenvolvimento nos termos de Pierre Bourdieu, ao categorizar o que é um campo científico:

O campo científico é um lugar de luta concorrencial e o que está em jogo é o monopólio da autoridade cientifica definida como capacidade técnica e poder social; ou, se quisermos, o monopólio da competência científica, compreendida enquanto capacidade de falar e de agir legitimamente (isto é, de maneira autorizada e com autoridade), que é socialmente outorgada a um agente determinado. (BOURDIEU, 1983, p. 122).

Assim, podemos entender o campo proposto por Bourdieu (1983) como uma grande arena onde permeiam diferentes padrões cognitivos que orientam os agentes nos processos de entendimento e inserção na realidade. Cada um desses padrões cognitivos é constituído por princípios, normas, valores, tradição, crenças que, ao serem compartilhados pelos agentes, permite-os que conheçam o mundo sob um processo cognitivo. Esse compartilhamento gera uma intersubjetividade entre os agentes, construída por interações 
ao longo do tempo e que não apenas limita ou capacita os atores no processo de entendimento da realidade social, mas define sua realidade social. Essa intersubjetividade se constitui com e na linguagem.

No entanto, é importante dizer que esse compartilhamento de sentidos e significados não é suficiente para que exista um equilíbrio ou consenso entre tendências concorrentes. Ou seja, dentro de um padrão cognitivo podem existir, nos termos de Bourdieu (1983), ideias dominantes e ideias dominadas - nos dois casos, as ideias devem ter autoridade e legitimidade para evocar a verdade. Quando ocorre de uma ideia ser dominante em relação às outras é porque seus agentes conseguem moldar a realidade em torno de significados autorizados (científicos ou não), tornando muito difícil, aos seus oponentes, desconstruí-las. Isso não invalida, contudo, a existência de uma intersubjetividade entre elas.

É sob essa perspectiva que se buscará entender de que maneira o desenvolvimento internacional estabelece os termos do campo da CID que, nascido de forma tímida nos anos 1940, progressivamente se consolidou como um grande mecanismo de ordenação das relações estabelecidas entre os países do Norte e do Sul e logo constituiu-se como um meio capaz de envolver Estados e sociedades por meio de programas e financiamentos de políticas públicas de desenvolvimento, bem como Estados e sociedades que os recebem. Tudo isso traduzido em uma miríade de três tipos de atores (beneficiários, doadores e mediadores) com identidades, interesses, preferências e objetivos próprios, orientados por "motivações políticas, econômicas, de segurança nacional, por razões humanitárias, ambientais ou morais" (MILANI, 2018, p. 24).

Em termos temporais, alguns momentos podem ser considerados marcantes nesse processo. Superada a fase da "incubação do desenvolvimento" (período correspondente ao nascimento da CID até o início dos anos 1960) (LANCASTER, 2007) (RIST, 2008), “os principais países doadores decidiram criar suas próprias agências bilaterais de cooperação para o desenvolvimento" (MILANI, 2018, p. 41). O surgimento desses novos atores marcou o início de uma divisão do trabalho no campo da CID: as agências bilaterais passam a exercer o papel de promover a assistência técnica e a ajuda orçamentária na modalidade da concessão; as agências multilaterais, que já ocupavam a cena, assumiram o papel de apoiar e gerir projetos, 
enquanto os bancos multilaterais seguiram a função de principais financiadores no aporte de grandes volumes de recursos. Nesse momento, tais atores se guiavam basicamente por três temas: Direitos Humanos, Descolonização e Desenvolvimento.

Importante dizer que

[...] as noções de cooperação internacional e desenvolvimento acompanham a própria história do sistema econômico capitalista, das relações coloniais, do projeto pretensamente universal da modernidade e, mais contemporaneamente, associam a CID ao liberalismo multilateral nas relações internacionais. Ambas as noções cooperação internacional e desenvolvimento - dizem respeito ao ideal de progresso econômico e solidariedade social, bem como à necessidade de construção de amplos consensos políticos entre as nações. (MILANI, 2018, p. 33).

Assim, a cooperação - como principal alternativa para um país se desenvolver apresenta-se como uma necessidade histórica do capitalismo, nuance do pensamento liberal na política internacional e elemento central dos processos de modernização nos diferentes continentes (BENDIX, 1996) (RIST, 2008) (MILANI, 2018). Os países recebedores da cooperação se tornaram campo de políticas públicas de reformas modernizantes que os permitam ascender ao grupo das nações ditas modernas - ou desenvolvidas. Assim, é nessa lógica e mobilizando argumentos de alguns autores (BENDIX, 1996) (RIST, 2008) (MILANI, 2018) que se pode dizer que a CID desempenha, ao mesmo tempo, o papel integrador e legitimador dos ideários do capitalismo e da modernização social. A ONU, nesse contexto, manifesta-se como um pilar no processo de legitimação política e multilateral da CID, mas não de forma tão evidente quanto parece.

Salles (2015) detalha que a autoridade sobre a agenda do desenvolvimento internacional, importante elemento de estruturação da arquitetura da CID, foi, num primeiro momento, alvo de intensa disputa entre o Banco Mundial e a ONU. O ponto crítico desse processo foi o reconhecimento de que "existiam diferentes caminhos possíveis para o desenvolvimento e que a escolha do melhor caminho estava nas disputas e jogos travados pelos próprios agentes do campo" (SALLES, 2015, p. 349). A Comissão Pearson, realizada em 1969 , teria apontado alguns elementos desse jogo, "evidenciando que não bastava promover políticas de ajuda para o desenvolvimento, mas que essas políticas deveriam ser eficientes e, 
portanto, seguir certos critérios estabelecidos por aqueles engajados nessas práticas" (SALLES, 2015, p. 349).

As ponderações da Comissão Pearson abrem espaço para o surgimento do conceito de Ajuda Oficial para o Desenvolvimento, para o reconhecimento da OCDE (Organização para Cooperação e Desenvolvimento Econômico) como ator central na definição do objeto do desenvolvimento internacional, bem como os atores elegíveis para a sua atuação. Por ajuda oficial ao desenvolvimento (AOD), entende-se:

[...] as doações e os empréstimos concedidos a países e territórios na Parte I da lista de destinatários beneficiados (países em desenvolvimento) do CAD (Comitê de Assistência ao Desenvolvimento), os quais: (a) sejam garantidos por um setor oficial; (b) tenham a promoção de desenvolvimento econômico e bem-estar como objetivos principais; (c) sejam realizados em termos financeiros concessionais (se um empréstimo tem um elemento de doação de pelo menos $25 \%$ ). Além de fluxos financeiros, a cooperação técnica é incluída na ajuda. Doações, empréstimos e créditos para propósitos militares são excluídos. (OCDE, [s.d.]).

Pode-se dizer que esse esforço por definir o objeto do desenvolvimento internacional atribui papeis aos atores e explicita disputas no campo da CID pela autoridade do conceito de desenvolvimento internacional que, por sua vez, guiará o modus operandi dos fluxos e agentes envolvidos. Após a Comissão Pearson, essa autoridade acaba se centrando nas mãos da OCDE e do Banco Mundial. A primeira, coordenando o rol de agentes doadores, os fluxos permitidos e o padrão de políticas a serem implementadas, de forma que se tivesse algo próximo de um certo padrão reproduzido no âmbito das transações multilaterais. Ao Banco Mundial, como poderá ser visto logo adiante, estava a capacidade financeira de implementar, monitorar e garantir o alcance de resultados.

Acreditava-se que, dessa maneira, se criariam condições para assegurar que a assistência para o desenvolvimento multilateral prevalecesse àquela de natureza bilateral, sob o receio de que, por meio desta última, os agentes do campo perderiam o controle sobre a operacionalização do desenvolvimento, tendo em vista que outros interesses poderiam desviar o foco dos recursos transferidos como, por exemplo, a existência de agendas concorrentes da lógica do desenvolvimento e que estariam "governadas por considerações diplomáticas ou comerciais" (PEARSON, 1969, p.23). Nessa lógica, várias estratégias 
começaram a ser pensadas para desencorajar os arranjos bilaterais de assistência ao desenvolvimento, fortalecendo aquele de caráter multilateral.

\begin{abstract}
Para a ampliação do escopo de responsabilidades das organizações internacionais além de ajustes "mecânicos", como a própria expansão de pessoal, era necessária ainda "uma revisão radical" do seu modus operandi para uma definitiva conversão da condição de fórum de atores para a condição de agentes do desenvolvimento. Essa revisão deveria levar em conta, principalmente, a política interna de cada organização vis-à-vis as relações estabelecidas entre elas. Deveria ainda deixar claro quem eram os agentes do campo (quais as fronteiras de participação), quais os capitais por eles mobilizados e quais os tipos de laços institucionais e posições de hierarquia potencialmente estabelecidos. Não só isso, essa revisão proposta deveria colocar em questão o senso comum até então prevalecente sobre desenvolvimento e favorecer a emergência de uma visão de mundo (mais ou menos) comum a todos os agentes em todos os países, desenvolvidos e subdesenvolvidos; visão essa a ser mediatizada pelas organizações internacionais. (SALLES, 2015, p. 356).
\end{abstract}

Assim, percebe-se que esse esforço para consolidar a assistência multilateral ao desenvolvimento em detrimento da bilateral, alimentado pelo relatório da Comissão Pearson, foi um importante passo para a CID, pois acabou incentivando um dado ajuste na atuação das organizações internacionais por meio de algumas prescrições. Interessante que até a maneira como se dava a alocação de recursos foi deixando a lógica aleatória e, progressivamente, foi ganhando contornos específicos de uma agenda. Além dos setores tradicionais, temas como a redução da pobreza e infraestrutura se tornaram recorrentes. Uma engrenagem complexa e contraditória de funcionalidades e procedimentos foi, aos poucos, se desenhando. Se, no início do século XX as ações da CID se manifestaram predominantemente por meio de assistências ao desenvolvimento de caráter bilateral e emergencial, ao longo dos anos foi se traduzindo em um rol infindável de políticas públicas financiadas pelas instituições multilaterais para promover reformas administrativas, transferência de conhecimento, modernização de estruturas produtivas, financiamentos de projetos sociais, de infraestrutura, educacionais etc. Aos poucos, essas instituições multilaterais foram matizando o campo político em torno de um padrão normativo e uma disputa por autoridade e legitimidade nos campos técnico e financeiro.

O Banco Mundial e as Nações Unidas se tornaram protagonistas dessa disputa por autoridade e legitimidade, tanto no campo técnico, quanto no financeiro. O Banco Mundial 
capitalizava suas capacidades financeira e técnica por meio da implementação e do financiamento de projetos de modernização social e redução da pobreza. Esses projetos estavam em curso nos países em desenvolvimento nos anos 1960, em prol do fortalecimento de seus vínculos e do reconhecimento da sua capacidade de gerar resultados concretos - haja vista sua reconhecida experiência em coordenar a ajuda emergencial à Índia no período entre 1958 e 1968 (AKITA, 2014). As Nações Unidas, como meio de fortalecimento de seu vínculo com os países beneficiários da CID, utilizaram seu capital técnico para a construção daquilo que deveria ser a agenda de ação para a implementação de diretrizes de promoção do desenvolvimento. Assim, enquanto o Banco Mundial contava com recursos financeiros e técnicos para implementar intervenções de promoção do desenvolvimento, a ONU contava com o capital técnico capaz de estabelecer e indicar diretrizes daquilo que deveria ser o conteúdo desse desenvolvimento. No entanto, apesar de apresentar boa capacidade de proposição, a ONU possuía limitações para a implementação de suas propostas devido à escassez de recursos.

\footnotetext{
Isso confirmava uma divisão clara: à ONU não eram confiados os instrumentos "hard" de desenvolvimento, tais como assistência financeira e formulação de políticas macroeconômicas - isso tinha que ser preservado pelas instituições Bretton Woods com seu sistema de votos fechado e controlado pelos países industrializados ocidentais. À ONU cabia os instrumentos "soft" de cooperação, tais como ajuda no combate à fome, assistência técnica, temas relacionados a políticas sociais, crianças, mulheres e, mais recentemente, meio ambiente (SINGER, 1995, p. 380).
}

Essa divisão entre instrumentos hard e soft acabou sinalizando as limitações da ONU na coordenação da agenda de desenvolvimento e, por consequência do próprio campo da CID, abrindo espaço para que o Banco Mundial e, logo depois, também a OCDE o assumissem. Isso vai evidenciar a reprodução da assimetria decisória, assimetria esta que é interna a esses órgãos na própria dinâmica do sistema internacional, mais precisamente nas relações Norte/Sul.

A ONU é governada, pelo menos na área econômica, pela regra de um voto por pais, enquanto o sistema "Bretton Woods" é o sistema um-dólar-um-voto. Isso garante aos países financeiramente poderosos o firme controle das instituições de Bretton Woods e isso os incentiva a concentrar seus recursos e apoio nessas instituições ao 
invés de direcioná-los para o sistema ONU, onde eles têm sido voto minoritário desde a independência das jovens nações (SINGER, 1995, p. 383).

Assim, a tradicional dinâmica institucionalizada no âmbito da CID - em que os países do Norte são ofertantes e os países do Sul, recebedores - não foi algo casual, mas fruto de uma batalha política. O processo decisório interno ao Banco Mundial e à OCDE que guia os procedimentos de como devem ser feitos os aportes de recursos, reproduz-se no próprio sistema internacional e se torna mandatório da própria dinâmica da CID. Tanto Banco Mundial, quanto OCDE, assumiram controle do rol de doadores, maneira de empenho dos recursos financeiros, lógica de formulação das políticas a serem implementadas, bem como estratégias de monitoramento e avaliação das mesmas, conforme ilustrado na Figura 1:

Figura 1 - Elementos do Campo político da Cooperação Internacional para o Desenvolvimento

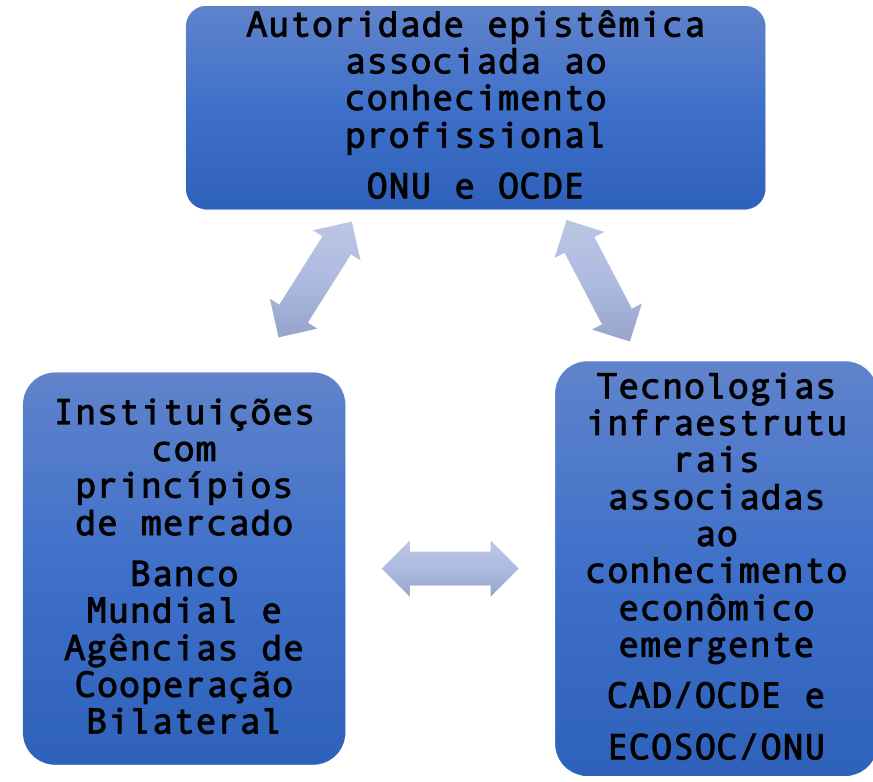

Fonte: Elaborado pela própria autora.

Na Figura 1 pode-se perceber que, dentre os elementos da Cooperação Internacional para o Desenvolvimento, existem algumas "forças" cujas representações são facilmente identificadas. A categoria "autoridade epistêmica associada ao conhecimento profissional" ${ }^{1}$ é

1 Para o aprofundamento do argumento que defende a Cooperação Internacional para o Desenvolvimento como um sistema, ver: AYLLON, Bruno. O sistema Internacional de Cooperação ao Desenvolvimento e seu estudo nas Relações Internacionais: a evolução histórica e as dimensões 
representada pelas figuras das organizações internacionais, ou seja, a ONU e a OCDE, que travam a batalha pela doxa do campo; as "instituições com princípios de mercado" é representada pelo Banco Mundial, que oferece créditos para o financiamento de políticas públicas de infraestrutura, de reformas administrativas e de modernização social ${ }^{2}$ (atualmente, também se percebe, nesse setor, um forte protagonismo do setor privado); por fim, a categoria "tecnologias infraestruturais associadas ao conhecimento econômico emergente" é representada pelo próprio CAD/OCDE e o ECOSOC/ONU. Esses dois últimos atores são aqueles que disputam espaço conforme o capital disponível. Já o nomos (lei fundamental) é representado pela modernização social que se universaliza por meio do desenvolvimento disseminado pelas agências que disputam a doxa do campo.

Nos anos 1970, contudo, vê-se movimentos paradoxais no campo da CID, pois há uma fragilização da crença naquilo que os resultados são capazes de produzir em função da crise de endividamento vivenciada pelos países do Sul. Por outro lado, nesse mesmo período, se iniciaram processos de sofisticação metodológica de gestão e implementação de projetos que perduram até hoje. Como resultado, se tem inovações na gestão do Banco Mundial por meio da alteração de sua estrutura interna e pela implementação de um novo instrumento de metas de empréstimo, o Country Program Paper. Uma das situações que mais diretamente demonstrava que a ideia de desenvolvimento, concebida no âmbito do Banco Mundial e OCDE, não estava resultando no previsto era o que ocorria, por exemplo, na América Latina e Caribe.

Após anos de políticas públicas baseadas no modelo de modernização social e crescimento econômico, nos anos 80, o Produto Interno Bruto da América Latina e do Caribe deixou de crescer, apresentando inclusive taxas negativas em alguns anos. Ao mesmo tempo, o índice de pobreza e de exclusão social aumentou de forma assustadora. Segundo o Banco Mundial, em 1985, a América Latina e o Caribe registravam 19\% da população abaixo da linha de pobreza (o que significava 70 milhões de pessoas) e $12 \%$ da população se encontrava

teóricas. In: Revista de Economia e Relações Internacionais / Faculdade de Economia da Fundação Armando Alvares Penteado. - Vol. 5, n. 8 (2006) - São Paulo: FEC-FAAP, 2005.

${ }^{2}$ Atualmente, também se percebe uma forte presença de atores privados no financiamento de políticas públicas no setor de infraestrutura. 
abaixo da linha extrema de pobreza (o que correspondia a 50 milhões de pessoas). (BANCO MUNDIAL, 2003, p. 29). No caso do Brasil, por exemplo, ao mesmo tempo que a sua economia passou a ocupar o nono lugar no ranking mundial, seus indicadores de Desenvolvimento Humano aproximaram-se daqueles verificados nos mais pobres países da África.

Tem-se, nesse contexto, um esgarçamento daquilo que se estava entendendo como desenvolvimento internacional - por parte do Banco Mundial/OCDE -, bem como a evidenciação das contradições nos resultados alcançados a partir das políticas públicas implementadas e as reclamações, por parte dos países do Sul, em relação às condicionalidades macroeconômicas trazidas pelos programas de ajuste estrutural, intervindo diretamente nas suas políticas desenvolvimentistas. Assim, de forma geral, as políticas públicas implementadas a partir da agenda da CID passaram a integrar, nos anos 1980, os programas de ajuste estrutural, alterando o discurso da cooperação. Este se voltou para a defesa de "condicionalidades políticas":

Para que os países em desenvolvimento pudessem receber ajuda oficial dos países doadores, teriam de se submeter a pacotes de austeridade fiscal, financeira e econômica que seguiam a receita ideológica e teórica do Estado mínimo, bem como parâmetros políticos do Consenso de Washington, ou seja, redução e racionalização do setor público, implementação de políticas macroeconômicas segundo os preceitos do FMI e do Banco Mundial, abertura das economias nacionais ao comércio internacional, abandono dos modelos nacional-desenvolvimentistas. (MILANI, 2018, p. 56).

Tais preceitos foram disseminados, legitimados e reforçados mesmo após a queda do muro de Berlim e fim da Guerra Fria, mas provocaram uma reorientação da CID a partir dos anos 1990 em função de intensos questionamentos quanto aos resultados auferidos. Até o final dos anos 1980, as organizações multilaterais atuantes no campo não conseguiram encerrar as críticas levantadas à forma como a operacionalização do desenvolvimento, por parte do Banco Mundial, estava operando em cada uma das etapas do seu ciclo - concepção da política pública, implementação, gestão, monitoramento e avaliação. Ao mesmo tempo, não conseguiram emplacar os termos de uma agenda alternativa, principalmente aquela propagada pela ONU que tentava dissociar desenvolvimento, lógica de mercado e indicadores econômicos de mensuração, como o Produto Interno Bruto, levando em conta uma concepção 
de desenvolvimento "mais humana", em que os problemas fundamentais da pobreza seriam levados em consideração.

\section{A AGENDA DA COOPERAÇÃO NO PÓS-GUERRA FRIA, QUESTIONAMENTOS AO DESENVOLVIMENTO INTERNACIONAL E O ENFRAQUECIMENTO POLÍTICO DO BANCO MUNDIAL E DA OCDE}

Nesse jogo, nos anos 1990, as Nações Unidas, por meio dos relatórios “Agenda para a Paz" (1992) e "Agenda para o Desenvolvimento" (1994), reconheceram a "natureza multidimensional do desenvolvimento em torno de cinco eixos principais: a paz como seu fundamento, o desenvolvimento econômico como base para o progresso, a sustentabilidade ambiental, a justiça social e a democracia" (MILANI, 2018, p. 57) ${ }^{3}$. Essa extensão do conceito de desenvolvimento implicou igualmente numa diversificação temática da agenda da ONU no âmbito da CID (incluindo temas como mudança climática, combate a pandemias, proteção da biodiversidade, minoração da pobreza e difusão das microfinanças), alterando a maneira de conceber e implementar programas de políticas públicas nos países do Sul. A lógica dos mercados livres e do Estado mínimo é mantida, mas agora redimensionada para a gestão da interdependência econômica, favorecendo os diálogos sobre políticas públicas (policy dialogues) e programas de formação (capacity-building).

Segundo Milani (2014; 2018); Rist (2008); Ayllón (2014); Besharati e Esteves (2015); Renzio e Seifert (2014), três temas principais polarizaram as atenções da CID nos anos 1990. O primeiro deles foi o lançamento do Índice de Desenvolvimento Humano (IDH) como novo parâmetro de mensuração do desenvolvimento em detrimento do Produto Interno Bruto (PIB), legitimando o entendimento multidimensional do desenvolvimento e do tratamento da pobreza e ofuscando a centralidade do debate estrutural e político sobre as desigualdades entre países. Em segundo lugar, tem-se a pauta de temas globais e suas discussões no âmbito

\footnotetext{
${ }^{3}$ Para acessar informações sobre os relatórios mencionados, conferir Nações Unidas, Assembleia Geral, "Na Agenda for Development", documento A/48/935, 6 de maio de 1994. Ver também: http://www.undemocracy.com/A-49-665.pdf.
} 
das grandes conferências realizadas: Conferência das Nações Unidas sobre o Ambiente e Desenvolvimento (1992), Conferência Mundial sobre Direitos Humanos (1993), Conferência Internacional sobre População e Desenvolvimento (1994), Cimeira Mundial sobre Desenvolvimento Social (1995), Quarta Conferência Mundial sobre a Mulher (1995), Segunda Conferência das Nações Unidas sobre Estabelecimentos Humanos - Habitat II (1996) 4 .

Tais conferências trazem três contribuições: chamam atenção para a importância da inclusão de novos temas na agenda internacional, agora menos tensionada em função do fim da Guerra Fria; discutem os mecanismos de implementação, monitoramento e avaliação das políticas públicas e permitem o acesso de uma nova rede de stakeholders, como as cidades, movimentos sociais e organizações não-governamentais. O terceiro tema diz respeito aos Objetivos de Desenvolvimento do Milênio (ODMs) cujo conteúdo foi grande parte redigido pela OCDE, mas com participação das Nações Unidas, tendo como referência diálogos estabelecidos nas diversas conferências mencionadas acima ${ }^{5}$.

No entanto, é importante destacar que o documento dos ODMs tem um antecedente. Os vários documentos produzidos a partir das conferências realizadas pela ONU ao longo dos anos 1990 se tornaram referência para a produção do Shaping the 21st Century - the Contribution of Development Co-operation, organizado pela OCDE e adotado na Quarta Reunião de Alto Nível do Comitê de Assistência ao Desenvolvimento, em 1996. Esse documento, produzido pela OCDE, ofereceu subsídios para que uma publicação conjunta entre OCDE, ONU, FMI e Banco Mundial fosse feita: a Better World for all, considerada uma prévia dos ODMs em termos de conteúdo e proposta de agenda de desenvolvimento. Assim,

Logo antes da histórica Cúpula do Milênio, a OCDE, a ONU, o Banco Mundial e o FMI divulgaram relatório chamado Better World for all, propondo um marco de objetivos quase idênticos aos que vieram a ser os Objetivos de Desenvolvimento do Milênio.

\footnotetext{
${ }^{4}$ Publicado pelo Departamento de Informação Pública das Nações Unidas DPI/1825/Rev. 7. Junho de 1999.

${ }^{5}$ Os objetivos de Desenvolvimento do Milênio (ODM) surgiram da Declaração do Milênio das Nações Unidas, adotada por 191 Estados-membros de 2000. Cf. NAÇÕES UNIDAS. Os Objetivos de Desenvolvimento do Milênio. Disponível em: http://nacoesunidas.org/tema/odm/. Acesso em: 20 dez. 2020. Os Objetivos de Desenvolvimento Sustentável seriam o avatar de 2015, uma vez que se constroem sobre o legado dos ODM e, conforme anuncia a própria ONU, devem concluir o que os ODM não conseguiram alcançar. Cf. NAÇÕES UNIDAS. Os Objetivos de Desenvolvimento Sustentável. Disponível em: https://nacoesunidas.org/pos2015/agenda2030/. Acesso em: 20 dez. 2020.
} 
Eles se baseavam, em grande parte, nos compromissos feitos em várias conferências principais da ONU nos anos 1990, bem como nos objetivos para o desenvolvimento internacional propostos pelo DAC no documento Shaping the 21st century. (BESHARATI e ESTEVES, 2015, p. 321).

Do ponto de vista de Besharati e Esteves, a autoria dos documentos gerados a partir das conferências levanta uma questão política entre as instituições assinaladas - OCDE, Banco Mundial, FMI e ONU - que diz respeito diretamente ao campo da CID: "quais seriam os facilitadores e, fundamentalmente, como [seria] financiado e quem [seria] o responsável por [esses] novos compromissos internacionais?" (BESHARATI e ESTEVES, 2015, p. 308). Como bem coloca Sachs (2005), na tradicional agenda da Cooperação Internacional para o Desenvolvimento, as metas de desenvolvimento estavam sob a responsabilidade dos países do Norte por meio da AOD e, com os ODMs, tem-se uma vaga responsabilização dos países do Norte, bem como um frágil sistema de monitoramento (BESHARATI e ESTEVES, 2015).

Nessa linha de raciocínio, tem-se que a ONU, por meio dos ODMs, tenta assumir o comando do campo político da CID junto à OCDE, sendo responsável pela agenda de promoção do desenvolvimento, acatada por 191 países presentes na Cúpula do Milênio no dia 08 de setembro de 2000. A ONU também acaba chamando para si o gerenciamento dos instrumentos necessários para a implementação dos programas norteadores das políticas públicas, ou seja, por meio da formulação de indicadores, da sistematização da base de monitoramento, de avaliação e do gerenciamento dos fundos de financiamento. No entanto, por mais bem intencionada que tenha sido a agenda dos ODMs, eles não foram apresentados como universais, nem amplamente debatidos. Por essas razões, esse foi um processo considerado top-down, que não problematizou a raiz das principais tensões presentes na relação Norte/Sul e da concepção linear de desenvolvimento propagada pelo Banco Mundial. Seus resultados foram tímidos, motivando as Nações Unidas a trabalhar em uma nova agenda de desenvolvimento, lançada em 2015, chamada Objetivos de Desenvolvimento Sustentável (ODS). Além das limitações da Agenda dos ODMs, um outro movimento da política internacional torna inevitável o lançamento dos ODS: o fortalecimento dos diálogos entre os países do Sul. 


\section{O FORTALECIMENTO DA COOPERAÇÃO SUL/SUL E AS PRESSÕES EXERCIDAS NO CAMPO POLÍTICO DA CID: REDEFININDO FRONTEIRAS DO DESENVOLVIMENTO INTERNACIONAL}

Pensar uma nova agenda de desenvolvimento por meio de um processo mais colaborativo com os países do Sul, em termos mais universais e com posicionamento crítico em relação ao que estava sendo praticado no âmbito dos diálogos Norte/Sul, fez-se inevitável por parte da ONU por três motivos. Primeiro, em função da intensificação dos diálogos estabelecidos entre os países do Sul nesse e em outros contextos, fruto do desdobramento desse processo. A Cooperação Sul/Sul é discutida no presente artigo para que seja possível entender que aquilo que se desenvolveu no início do alinhamento dos países do Sul em Bandung, em 1955 (como uma cooperação para o apoio mútuo e de reivindicação pelo estabelecimento de uma Nova Ordem Econômica Mundial (NOEI), nos termos da Declaração de 1974), transformou-se em nível de escopo e de valor. A seguir, os principais marcos desse processo serão evocados para que o argumento fique melhor entendido.

Desde Bandung até os dias de hoje, um sem número de diálogos marcaram as relações entre os países do Sul, criando, na agenda, uma ampla gama de formas de cooperação, desde os espaços multilaterais de negociação (por exemplo, o G-77 ou o G-20 comercial) até a formação de coalizões políticas (como IBAS e BRICS, por exemplo), passando inclusive pela promoção do comércio Sul-Sul (ALADI, SADC), pela construção de espaços regionais de integração (Mercosul, UNA-SUL), pelo financiamento de projetos de infraestrutura via empréstimos subsidiados, até modalidades de transferência de tecnologia, intercâmbio de experiências de campo das políticas públicas e cooperação técnica por meio de ministérios, agências, unidades subnacionais, universidades e organizações não-governamentais.

Sem dúvida, a fundação da UNCTAD (United Nations Conference on Trade and Development), em 1964, foi considerada um passo importante para a consolidação institucional da CSS e o berço de surgimento do G77 (grupo dos 77 países em desenvolvimento). Nos anos 1960 e 1970, a UNCTAD foi considerada uma das mais importantes plataformas de coordenação dos países em desenvolvimento, de seus interesses, 
de formulação de políticas comerciais e de negociação com os países desenvolvidos. Tanto a UNCTAD quanto o G77 são considerados movimentos estruturantes da ideia de Nova Ordem Econômica Internacional (New International Economic Order), cuja Declaração de criação ocorreu em 1974 e que também se tornou outra importante etapa para o processo de institucionalização da CSS.

Em 1974, no âmbito do PNUD, foi criada a Unidade Especial para o CTPD (ABC, 2017). Em 1978, a AGNU (Assembleia Geral das Nações Unidas) outorga mandato ao PNUD, por meio da Unidade Especial de CSS, para coordenar toda a CSS no Sistema das Nações Unidas, tendo como atribuições

[...] fomentar a cooperação técnica e econômica entre os países em desenvolvimento; promover o reconhecimento e inclusão da CSS como uma alternativa para a promoção do desenvolvimento; ser catalisador para necessidades inovadoras da CSS; mobilizar apoio mundial; gerir o Fundo Fiduciário para a CSS, o Fundo Fiduciário Pérez Guerrero para a Cooperação Técnica para o Países em Desenvolvimento e para a Cooperação Econômica entre Países em Desenvolvimento; por fim, também se responsabilizar por formular o Marco da CSS no âmbito do PNUD (NAÇÕES UNIDAS, 1978, s/p).

As diretrizes de ação desse grupo de trabalho foram consubstanciadas no Plano de Ação derivado da Conferência das Nações Unidas sobre a Cooperação Técnica entre os Países em Desenvolvimento ${ }^{6}$ realizada em Buenos Aires em 1978 - o PABA (Plano de Ação de Buenos Aires) -, considerado o primeiro documento que sistematiza um conjunto de diretrizes aos países em desenvolvimento que desejam cooperar ${ }^{7}$. Um ponto específico chama atenção nesse documento: a retomada do papel da cooperação técnica, discutida em Bandung, e a reafirmação da capacidade desse instrumento de permitir que os países em desenvolvimento resolvam os seus problemas com criatividade e autonomia (ESTEVES; ASSUNÇÃO, 2014).

Sem nenhuma controvérsia entre os vários autores que discutem a CSS, o PABA é considerado o seu documento simbólico, pois consagra o instrumento da cooperação técnica e seu princípio realizador - a horizontalidade de diálogo entre os países do Sul -, conferindo-

${ }^{6}$ Participaram dessa conferência 138 países, 45 ministros, 41 vice-ministros e 81 diretores de departamentos de cooperação e planejamento.

${ }^{7}$ O conteúdo do PABA se tornou diretriz interna de ação da ONU/PNUD mediante a Resolução $\mathrm{n}^{\circ} 22 / 134$. 
Ihe o atributo de ser um "meio para fomentar uma cooperação mais efetiva entre países em desenvolvimento" e a CSS como "força decisiva para organizar e fomentar o desenvolvimento mediante transferência de conhecimentos e a prática de compartilhar experiências" (ONU, 1978). Ou seja, o PABA, ao reconhecer a existência da cooperação entre países em desenvolvimento, legitima-a por meio de diretrizes que contribuem para a institucionalização tanto do processo, quanto de conceitos que se tornaram referência para a CSS até os dias atuais.

No entanto, se o início dos anos 1970 se constituíram como um período fértil para o florescimento da CSS, não se pode dizer o mesmo do final dessa mesma década e dos anos 1980. Um conjunto de fatores (principalmente de ordem econômica) que reacende nos Estados Unidos uma nova chama de retomar ou reafirmar seu papel hegemônico tem um efeito, em alguma medida, desmobilizador no Movimento dos Países Não-Alinhados e, por consequência, na própria configuração da Nova Ordem Econômica Internacional (NOEI). Em função disso, os anos 1980 são marcados por uma desarticulação do Sul Global e por uma desaceleração do seu ímpeto reativo ao Sistema de Governança da Cooperação Internacional para o Desenvolvimento vigente (MAWDSLEY, 2012) (AYLLÓN, 2014).

Tal contexto tem como reflexo um relativo processo de deslegitimação das demandas dos países em desenvolvimento sob o argumento de eles coadunarem com a lógicas das ações que guiam os países do Norte na implementação de políticas de promoção ao desenvolvimento, por aceitarem replicá-las em suas esferas domésticas. Dessa maneira, não haveria sentido promover reinvindicações de mudanças no sistema econômico internacional, já que esta era a forma como as políticas dos países em desenvolvimento estavam sendo implementadas (AYLLON, 2014). Assim, nesse período, identifica-se um esvaziamento da NOEI e de qualquer outro arranjo contestatório promovido pelos países do Sul.

O fato é que, a partir da segunda metade dos anos 1990, alguns autores, como Ayllón (2009; 2014); Besharati e Esteves (2015); Esteves e Assunção (2014); Renzio e Seifert (2014) e Mawdsley (2012), identificam uma lenta recuperação da Cooperação Sul/Sul, sendo parte desse desempenho atribuído ao relativo crescimento econômico de alguns países em desenvolvimento mais avançados, pois tiveram suas capacidades internas relativamente 
fortalecidas. Além disso, também é identificada a intensificação e priorização do uso da CSS como alternativa à tradicional CNS, por parte daqueles países tradicionalmente posicionados como receptores de alto volume de AOD. O lançamento do documento intitulado Novas Direções para a CTPD, em evento organizado pela ONU em 1995, é considerado uma alavanca dessa nova dinâmica observada. Não apenas pelas novas diretrizes estabelecidas para a Cooperação Técnica entre Países em Desenvolvimento, mas também por encorajar um grupo de 22 nações ${ }^{8}$ a assumir o protagonismo na cooperação em função de suas condições políticas e econômicas. Mas aquela dimensão política que marcou a CSS no início da mobilização do Sul Global, consagrando-a como um movimento de contestação do sistema de governança vigente, teve seu brado e encorajamento enfraquecido para uma agenda técnico-burocrática da própria CID.

Autores como Ayllón (2014), Behsarati e Esteves (2015), Milani (2012), Souza (2014), Esteves e Assunção (2014), Renzio e Seifert (2014) e Mawdsley (2012) indicam que esse novo fôlego assumido pela CSS no início dos anos 2000 é justificado pela articulação dos BRICS e o papel que eles passam a desempenhar não apenas na dinâmica da política internacional do Sul Global, mas nas relações internacionais de forma geral. Inegável que o arranjo estabelecido entre Brasil, Rússia, Índia, China e África do Sul teve efeitos diretos no sistema de governança da CID. Bem possivelmente em função disso, mas também em função de outros fatores que serão discutidos, pode-se perceber que a primeira década dos anos 2000 foi marcada por um grande esforço dos países do Sul de se organizarem coletivamente, utilizando principalmente as plataformas para discutir interesses e estratégias a serem adotadas prioritariamente, como, por exemplo, as cúpulas do G-77 e China. Os ODMs tinham aberto a brecha na governança da CID e essa oportunidade não poderia ser perdida para alavancar novamente a CSS. Tudo isso será emocionante, porque, como poderá ser observado, isso se reverterá no sistema de governança da CID em um verdadeiro campo de batalha entre os cavaleiros do Sul, da ONU e da OCDE.

\footnotetext{
${ }^{8}$ Brasil, Chile, Colômbia, México, Costa Rica, Cuba, Peru, Trinidad-Tobago, China, India, Indonésia, Malásia, Turquia, Egito, Tunísia, Coreia do Sul, Tailândia, Nigéria, Gana, Senegal, Malta e Ilhas Maurício.
} 
No ano seguinte, em 2009, ocorreu a II Conferência de Alto Nível das Nações Unidas sobre Cooperação Sul/Sul em Nairóbi, com a finalidade de examinar os 30 pontos do Plano de Ação de Buenos Aires (1978). Pode-se dizer que essa conferência, nos marcos dos anos 2000, é uma das mais importantes para a cooperação estabelecida entre os países do Sul por três principais razões. A primeira delas é a quebra do jejum de quase 30 anos, por parte das Nações Unidas, na promoção de um novo fórum de diálogo dos países do Sul após Buenos Aires em 1978; a segunda, como o próprio nome da Conferência sinaliza, justifica-se em termos institucionais, pois a Cooperação Técnica entre Países em Desenvolvimento (CTPD) torna-se a Cooperação Sul/Sul. Já a terceira razão refere-se à natureza do conteúdo do documento de encaminhamento que, além de estabelecer uma sólida análise do cenário então vivenciado pelos países do Sul, recomenda diretrizes a serem adotadas por eles, "ressaltando a cooperação Sul/Sul como importante elemento de cooperação internacional para o desenvolvimento ao oferecer oportunidades viáveis aos países em desenvolvimento em sua busca individual e coletiva de crescimento econômico e desenvolvimento sustentável" (NAÇÕES UNIDAS, 2009).

Nessa linha, outros trechos do documento merecem ser destacados, sobretudo porque neles há uma evidente manifestação de apoio das instâncias e fundos orçamentários das Nações Unidas à "causa" da Cooperação Sul/Sul e da Cooperação Triangular, reconhecendo a sua importância estratégica, além de uma forte sinalização da necessidade de os países do Sul desenvolverem mecanismos próprios para a implementação das iniciativas de promoção do desenvolvimento - no sentido de que a CSS não é uma modalidade de AOD, mas deve cumprir uma agenda de cooperação própria guiada por demandas específicas dos países do Sul. Assim, eles mesmos são responsabilizados pela criação e pela manutenção de sistemas de monitoramento baseados em indicadores que mensurem bem a transformação da realidade sujeita às ações de desenvolvimento.

No documento de encaminhamento da Conferência, há um encorajamento da cooperação entre os países do Sul, inclusive na modalidade triangular. Além disso, é enfatizada a necessidade de os países em desenvolvimento melhorarem os seus sistemas nacionais de informação para avaliarem a qualidade e o impacto da CSS. Também foi 
reforçada a utilização da modalidade triangular, difundindo e compartilhando experiências e lições aprendidas. O discurso dessa Conferência deixa manifesta a ênfase dada ao argumento da efetividade da CID:

Reafirmamos o papel fundamental das Nações Unidas, incluindo seus fundos, programas, agências especializadas e comissões regionais, no apoio e promoção da cooperação entre os países em desenvolvimento, reiterando que o país tem a responsabilidade primária pelo seu próprio desenvolvimento. Reiteramos a resolução 33/134 de 19 de dezembro de 1978, endossando o Plano de Buenos Aires de Ação, que constituiu um marco importante na evolução da Sul-Sul e cooperação triangular.

Reconhecemos as diferentes histórias e particularidades da Cooperação Sul-Sul e reafirmamos nossa visão da cooperação Sul-Sul como uma manifestação de solidariedade entre os povos e países do Sul que contribui para o bem-estar nacional, autossuficiência nacional e coletiva e o alcance de metas de desenvolvimento acordadas internacionalmente, incluindo os Objetivos de Desenvolvimento do Milênio. Os países do Sul têm que estabelecer sua própria agenda sendo guiados por princípios do respeito à soberania nacional, à apropriação e independência nacional, igualdade, não-condicionalidade, não-interferência nos assuntos internos e benefício mútuo.

Ressaltamos que a cooperação Sul-Sul não é um substituto, mas sim um complemento à cooperação Norte-Sul.

Reconhecemos o valor do apoio crescente oferecido pelos países desenvolvidos, organizações internacionais e sociedade civil aos países em desenvolvimento, a pedido destes, na melhoria das suas competências e capacidades nacionais através de mecanismos triangulares de cooperação, incluindo apoio direto ou compartilhamento de custos, acordos, projetos conjuntos de investigação e desenvolvimento, formação de programas e apoio aos centros Sul-Sul, bem como ao fornecimento de conhecimento, experiência e recursos necessários, de modo a ajudar outros países, de acordo com suas prioridades e estratégias nacionais de desenvolvimento.

A cooperação Sul-Sul não deve ser entendida como Ajuda Oficial para o Desenvolvimento. É uma parceria entre iguais baseada na solidariedade. Nesse sentido, reconhecemos a necessidade de melhorar a eficácia do desenvolvimento promovido no âmbito da Cooperação Sul-Sul, aumentando a responsabilidade mútua, transparência e coordenando suas iniciativas com outras áreas do desenvolvimento. (NAÇÕES UNIDAS, 2009).

Além da importância do trecho mencionado acima, outros excertos também merecem destaque, mas no momento não se tem espaço suficiente para abordá-los. De modo geral, o Documento de Nairóbi é um importante passo dado pelas Nações Unidas no tocante ao reconhecimento e à institucionalização para o fortalecimento da Cooperação Sul/Sul como alternativa de promoção do desenvolvimento do tradicional diálogo Norte/Sul. Tal reposicionamento da Cooperação Sul/Sul, além de um conjunto de práticas de promoção de 
desenvolvimento, também é fonte de orientação das Nações Unidas para a adoção de um conjunto de ajustes internos e tem um efeito que pode ser entendido numa perspectiva relativamente revisionista do sistema de governança vigente, que prioriza o atendimento dos interesses dos países do Norte. Além disso, considerando a realização dos Fóruns de Alto Nível sobre a Eficácia da Ajuda, organizados pela OCDE, percebe-se que os anos 2000 são marcados por dois processos paralelos: aqueles referentes ao esgotamento das reformas orientadas para o mercado e aqueles que se referem às abordagens em prol da pobreza, traduzidos nos ODMs (ESTEVES e ASSUNÇÃO, 2014). Mesmo assim, como será discutido adiante, a Declaração de Nairóbi influenciou, em alguma medida, algumas discussões e diretrizes adotadas no IV Fórum de Alto Nível sobre a Eficácia da Ajuda, realizado em Busan, em 2011.

Mas o ponto alto do processo de discussão dos novos contornos que o sistema de governança da Cooperação Internacional para o Desenvolvimento estava assumindo em função do crescente papel da CSS é o Quarto Fórum de Alto Nível para a Eficácia da Ajuda, realizado na cidade de Busan, Coreia do Sul, em 2011. Para muitos autores, é no Documento de Parceria de Busan (The Busan Partnership Document) que se tem o turning point da Cooperação Sul/Sul, por consagrá-la como legítima modalidade de Cooperação Internacional para o Desenvolvimento, tal como fica bem ilustrado no trecho abaixo:

\begin{abstract}
A complexa atual arquitetura da cooperação internacional para o desenvolvimento evoluiu do paradigma Norte-Sul. Diferentemente das tradicionais relações entre os provedores de ajuda e receptores, as nações em desenvolvimento e várias economias emergentes tornaram-se importantes provedores da Cooperação para o Desenvolvimento Sul-Sul [...] A Declaração de Paris não abordou a complexidade desses novos atores, mas a Agenda para Ação de Acra reconheceu sua importância e especificidades. Embora a cooperação Norte-Sul continue sendo a principal forma de Cooperação para o Desenvolvimento, a Cooperação Sul/Sul continua evoluindo, apresentando-se como alternativa adicional de recursos para a promoção do desenvolvimento. Em Busan, todos nós somos agora partes integrantes de uma nova e mais inclusiva agenda de desenvolvimento, na qual esses atores participam guiados por objetivos comuns, princípios compartilhados e compromissos diferenciais. Nessa mesma base, saudamos a inclusão da sociedade civil, do setor privado e de outros atores (OCDE, 2011 [Tradução nossa] [grifo nosso]) ${ }^{9}$.
\end{abstract}

9 "Today's complex architecture for development cooperation has evolved from the North-South paradigm. Distinct from the traditional relationship between aid providers and recipients, developing nations and a number of emerging economies have become important providers of South-South development cooperation [...] The Paris Declaration did not address the complexity of these new actors, whilethe Accra Agenda for Action recognized their importance and specificities. While North-South 
Sem dúvida, a CSS ter o reconhecimento da OCDE (aquela que deteve o monopólio dos marcos da ajuda internacional desde o final da II Guerra Mundial) é um importante marco. 0 fato é que reconhecer a legitimidade da modalidade Sul/Sul na promoção do desenvolvimento significou também assimilar o conjunto de valores que orientam essas interações no âmbito das instituições, bem como reposicionar os países em desenvolvimento nos processos decisórios das organizações envolvidas na agenda do desenvolvimento. Sumariamente, em outras palavras,

\footnotetext{
o documento final (i) reconhece o papel cada vez mais relevante da cooperação SulSul na ajuda internacional para o desenvolvimento; (ii) oferece um lugar destacado às novas práticas de cooperação para o desenvolvimento e (iii) propõe a construção da "Parceria Global para uma Cooperação para o Desenvolvimento Efetiva" (Global Partnership for Effective Development Cooperation), inscrita em uma nova parceria global para o desenvolvimento. (ESTEVES et al, 2012, sp.).
}

Mas os fatos não evoluíram de forma tão linear e simples como parece. Ao longo da reunião de Busan, uma intensa força tarefa foi realizada para garantir que as negociações fluíssem de forma que assinaturas de importantes países como China, Índia e Brasil fossem angariadas (SEIFERT e RENZIO, 2014). No entanto, a pretensa unidade de posicionamento, assegurada pelos processos de coordenação de políticas (que deveria ser a principal conquista das discussões realizadas em Busan), foi prejudicada pela dissidência em relação à expressão "compromissos diferenciais" (differential commitments) presente no documento final. China e Brasil deixaram claro que não assinariam a declaração sem que houvesse uma expressão explícita que reconhecesse a natureza voluntária dos parceiros do Sul no cumprimento dos compromissos específicos, metas e ações (SEIFERT e RENZIO, 2014). Ambos os países não avaliavam como justa a lógica da responsabilidade comuns, porém diferenciadas no sentido de que, juntamente com as potências emergentes, os provedores menores também poderiam

cooperation remains the main form of development cooperation, South-South cooperation. At Busan, we now all form an integral part of a new and more inclusive development agenda, in which these actors participate on the basis of common goals, shared principles and differential commitments. On this same basis, we welcome the inclusion of civil society, the private sector and other actors". (OCDE, 2011). 
cumprir um papel, aumentando o apoio para a erradicação da pobreza e complementando os recursos dos maiores doadores.

Dissidências, como as apresentadas pela China e pelo Brasil em relação ao documento final, também marcaram as discussões que sucederam a reunião de Busan, principalmente no âmbito da "Parceria Global para uma Cooperação para o Desenvolvimento Efetiva" (Global Partnership for Effective Development Cooperation). Essa organização, como recentemente mencionado, foi criada devido ao encaminhamento do IV Fórum para ser, ao mesmo tempo, uma grande plataforma unificada das modalidades de cooperação para o desenvolvimento (envolvendo tanto as modalidades Norte/Sul como a Sul/Sul) de forma que viabilizasse: a interlocução entre os stakeholders (governo, sociedade civil, setor privado e outros) da Cooperação Internacional para o Desenvolvimento; o intercâmbio de conhecimento e inovação; o acompanhamento de processos por meio de mecanismos de monitoramento e avaliação; o espaço para que novos parceiros e políticas possam ser desenvolvidos e intercambiados (GLOBAL PARTNERSHIP, 2018).

Diante do exposto, tem-se outros dois pontos importantes que podem ser considerados desdobramentos do fortalecimento da CSS: a oposição que todo esse movimento faz aos princípios do CAD/OCDE e do Banco Mundial, fragilizando-os em suas posições no campo da CID. Também contribuindo para essa fragilização, atingindo mais diretamente o papel do Banco Mundial e seus instrumentos hard, manifesta-se nas figuras do Banco da China e do Banco de Desenvolvimento dos BRICS. Se, antes, o Banco Mundial atrelava à sua capacidade de empréstimo financeiro a sua ingerência nas esferas domésticas dos países recebedores (orientando-os para que soubessem como executar esses recursos nos termos de concepção, implementação e monitoramento de políticas públicas), a possibilidade de se estabelecer novos diálogos de empréstimos com o Banco da China ou dos BRICS fragilizou essas condicionalidades.

Todos esses movimentos provocaram um relativo esvaziamento dos papeis desempenhados pelo Banco Mundial e OCDE, consagrados nos últimos anos como autoridades do campo, minando também suas autoridades para estabelecer sua ideia de desenvolvimento internacional como aquela dominante no campo. Abriu-se espaço para que 
agendas alternativas encampadas pela ONU ganhassem espaço, assim como o que aconteceu com o lançamento dos ODS em 2015. Com isso, pode-se concluir que o os diálogos estabelecidos entre os países do Sul conseguiram estabelecer pressão suficiente no campo da CID para que suas fronteiras fossem revistas, mesmo que não alteradas totalmente nos termos de uma Nova Ordem Econômica Internacional, e a ONU, muito atenta a esse processo, aproveitou para assumir a doxa do desenvolvimento internacional por meio dos ODS.

\section{CONSIDERAÇÕES FINAIS}

Fez-se a opção pelo modelo de desenvolvimento como elemento de entendimento da dinâmica do campo político da CID, pois o ideário da modernização social, ao se universalizar, torna o desenvolvimento o marco fundante e estruturante da CID. Nos termos de Bourdieu (1983), a modernização social é o nomos do campo, definindo papeis, regras e valores compartilhados pelos atores envolvidos no sistema, pois possui capacidade de oferecer, simultaneamente, uma orientação para as relações entre os agentes, ou seja, um modelo de cognição por meio do qual esses mesmos agentes conferem sentido a eles mesmos, às suas relações, à relação com o mundo e ao um princípio moral para o seu comportamento. Além disso, ele também pode ser considerado uma razão de ser da clivagem então estabelecida entre os países do Norte e do Sul, já que eles foram divididos não por sua posição geográfica (apesar da coincidência), mas porque são posicionados em gradações diferentes na escala do desenvolvimento, dividindo-se em países desenvolvidos e países em desenvolvimento. Por isso, a CID, ao consolidar essa clivagem orientando suas diretrizes nessa modalidade de divisão dos países, acaba sendo um elemento reforçador e de manutenção do status quo.

Assim, chega-se à primeira conclusão deste estudo: a adoção do modelo de desenvolvimento alternativo àquele que propagou a modernização social nos termos de Bendix (1996) seria uma alternativa não apenas para se problematizar a tradicional clivagem política e econômica existente no sistema internacional, mas para também contribuir para o estabelecimento de elementos concretos de alteração da dinâmica no campo político da CID. 
Assim, quando a ONU - por meio dos ODS - apresenta uma nova agenda de desenvolvimento, reconhecendo a dinâmica da CSS em processo de novo fôlego, e esta articulação cria uma instância de instrumentos hard a serviço de seus interesses e compartilhando elementos de sua visão de mundo, tem-se uma fragilização das fronteiras do campo da CID.

A partir disso, tem-se a segunda conclusão deste estudo, mesmo que não tenha sido objeto central desta análise: se os países do Sul se mobilizarem mais fortemente em um esforço conjunto de conferir maior concerto às suas práticas por meio de instâncias de divulgação, de sistemas de monitoramento e avaliação e de mecanismos de transparências de suas informações, isso pode contribuir para um processo de disseminação de um modus operandi específico da CSS. Não que essa padronização seja necessária e interessante, mas talvez seja um primeiro passo para facilitar processos de institucionalização. Ou seja, há a assimilação da prática da CSS por parte das organizações internacionais nos termos de suas burocracias, já que estas demandam, pela natureza de sua finalidade, um conjunto de mecanismos de gerenciamento para dar existência a um projeto ou a uma atividade específica, a começar pela própria discussão sobre rubricas orçamentárias. Tão elementar, tão burocrática, mas imagine-se um departamento da OCDE dedicado à CSS tendo que pensar sua execução orçamentária a partir de ações, atores e atividades tão heterogêneas e diversas quanto aquelas que existem no âmbito da CSS.

A partir desse último raciocínio, este estudo se encerra com uma antiga inquietação: em todos esses anos, desde o início da CID, pode-se perceber, de fato, sinais de desenvolvimento, nos termos materiais estabelecidos pelo Norte, nos países em desenvolvimento? Em quais bases? Pois, se o que se percebe é justamente um contínuo alargamento das agendas de desenvolvimento organizadas pela ONU, onde garantias cada vez mais imateriais são estabelecidas como indicadores de desenvolvimento, então desenvolvimento seria de fato garantido por obra, cidade, indústria, automóvel, etc. ou seria garantido por tolerância, respeito, dignidade, liberdade e autonomia? 


\section{REFERÊNCIAS}

AKITA, SThe Aid-India Consortium, the World Bank, and the International Order of Asia, 1958-1968, Asian Review of World Histories, vol. 2, n. 2, 2014, p.217-248.

BARNETT, Michael; FINNEMORE, Martha. Rules for the World: international organizations in global politics. Ithaca: Cornell University Press, 2004.

BENDIX, Reinhard. Construção Nacional e Cidadania - estudos de nossa ordem social em mudança. São Paulo: Editora da Universidade de São Paulo, 1996.

BESHARATI, Neissa; ESTEVES, Paulo. Os BRICS, a Cooperação Sul-Sul e o campo da cooperação internacional para o desenvolvimento internacional. In: Contexto Internacional. Rio de Janeiro, vol. 37, n.1, 2015, pp. 289-330.

BORDIEU, Pierre. Razões práticas sobre a teoria da ação. Campinas: Papirus, 1996.

BOURDIEU, Pierre. O campo científico. In: ORTIZ, Renato (org.). Sociologia. São Paulo: Ática, 1983.

ESTEVES, Paulo; MANAÍRA, Assunção. South-South cooperation and international development battlefield: between the oecd and UN. In: Third World Quarterly, vol. 35, n.10, 2014, 1775-1790.

ESTEVES, Paulo; ABREU, Aline; FONSECA, João; NIV, Amir; ASSUNÇÃO, Manaíra; URIAS, Filipe. A cooperação para o desenvolvimento: os BRICS e a política externa brasileira. Economia, Parlamentos, Desenvolvimento e Migrações. Rio de Janeiro, 2012.

FINNEMORE, Martha. National Interests in International Societ. Ithaca: Cornell University Press, 2004.

GIDDENS, Anthony. A constituição da sociedade. São Paulo: Martins Fontes, 1989.

LANCASTER, Carol. Foreign aid: diplomacy, development, domestic politics. Chicago: The University of Chicago Press, 2007.

MAWDSLEY, Emma. From recipients to donors: emerging powers and the changing development landscape. London: Zed Books Ltda, 2012. 
MILANI, Carlos R. S. Aprendendo com a História: críticas à experiência da Cooperação NorteSul e atuais desafios à Cooperação Sul-Sul. In: Caderno CRH. Salvador, v.25, n.65, 2012, p.p. 211-231.

MILANI, Carlos R. S. Organizações Multilaterais de desenvolvimento. Repensando a Cooperação Internacional para o Desenvolvimento. In: SOUZA, André de Mello (Org.). Repensando a Cooperação Internacional para o Desenvolvimento. Brasília: Instituto de Pesquisa Econômica Aplicada (IPEA), 2014.

MILANI, Carlos R. S. Solidariedade e interesse: motivações e estratégias na cooperação internacional para o desenvolvimento. Rio de Janeiro: FAPERJ, 2018.

NAIROBI OUTCOME (2010). Disponível em: http://southsouthconference.org/wpcontent/uploads/2010/01/GA-resolution-endorsed-Nairobi-Outcome-21-Dec09.pdfhttp://southsouthconference.org/wp-content/uploads/2010/01/GA-resolution-endorsedNairobi-Outcome-21-Dec-09.pdf. Acesso em: 20 jul. 2021.

PEARSON, Lester (Org.). Sócios no progresso: relatório da Comissão de Desenvolvimento Internacional. [s.I.]: APEC (versão traduzida), 1969.

PINO, Bruno Ayllón. Agentes transformadores da Cooperação para o Desenvolvimento: poderes emergentes e Cooperação Sul-Sul. Relaciones internacionales (La Plata), vol. 40, 2011.

PINO, Bruno Ayllón; O Sistema Internacional de Cooperação para o Desenvolvimento e seu estudo nas Relações Internacionais: a evolução histórica e as dimensões teóricas. In: Revista de Economia e Relações Internacionais. Vol.5, n.8, 2006, p.p 5-23.

RENZIO, Paolo de; SEIFERT, Jurek. South-South cooperation and the future of development assistance: mapping actors and options. In: Third World Quarterly, vol. 35, n. 10, 2014, pp. 1860-1875.

RIST, Gilbert. The History of Development: From Western Origins to Global Faith. 4. ed. Londres: Zed Books, Ltda, 2008.

SACHS, Wolfgang. Meio Ambiente. In: (Org.). Dicionário do Desenvolvimento guia para o conhecimento como poder. Petrópolis: Vozes, 2000.

SALLES, Fernanda Cimini. O papel da ONU e do Banco Mundial na consolidação do campo internacional do desenvolvimento. In: Contexto Internacional, vol.37, no 2, 2015, pp. 347373. 
SINGER, Hans W. Half a Century of Economic and Social Development Policies of the UN and Bretton Woods Institutions. The Pakistan Development Review. Winter, 1995, pp. 375-392. 